\title{
PENGARUH BAURAN PEMASARAN DAN KUALITAS PELAYANAN TERHADAP KEPUASAN KONSUMEN PADA GIANT DEPT STORE CABANG BSD TANGERANG
}

\author{
Denok Sunarsi \\ Program Sudi Menejemen, Fakultas Ekonomi, Universitas Pamulang, Tangerang Selatan, Banten. \\ Email Corespondent : denoksunarsi@unpam.ac.id
}

\begin{abstract}
This study aims to determine the effect of marketing mix and service quality on consumer satisfaction at Giant Dept Store BSD Tangerang Branch. The method used is explanatory research with analytical techniques using statistical analysis with regression testing, correlation, determination and hypothesis testing. The results of this study marketing mix significantly influence consumer satisfaction by $37.7 \%$, hypothesis testing obtained $t$ count> t table or (7.707> 1.984). Service quality has a significant effect on customer satisfaction by $46.1 \%$, the hypothesis test is obtained t count $>t$ table or $(9,153>1,984)$. Marketing mix and service quality simultaneously have a significant effect on customer satisfaction with the regression equation $Y=9,780+0,293 X 1+0,476 X 2$ and the contribution of effect is $53,8 \%$, the hypothesis test is obtained $F$ count $>F$ table or $(56,404>2,700)$.
\end{abstract}

Keywords : Marketing Mix, Service Quality, Consumer Satisfaction.

\begin{abstract}
Abstrak: Penelitian ini bertujuan untuk mengetahui pengaruh Bauran pemasaran dan kualitas pelayanan terhadap kepuasan konsumen pada Giant Dept Store Cabang BSD Tangerang. Metode yang digunakan adalah explanatory research dengan teknik analisis menggunakan analisis statistik dengan pengujian regresi, korelasi, determinasi dan uji hipotesis. Hasil penelitian ini Bauran pemasaran berpengaruh signifikan terhadap kepuasan konsumen sebesar 37,7\%, uji hipotesis diperoleh $t$ hitung $>t$ tabel atau $(7,707>1,984)$. Kualitas pelayanan berpengaruh signifikan terhadap kepuasan konsumen sebesar 46,1\%, uji hipotesis diperoleh $t$ hitung $>t$ tabel atau $(9,153>1,984)$. Bauran pemasaran dan kualitas pelayanan secara simultan berpengaruh signifikan terhadap kepuasan konsumen dengan persamaan regresi $Y=9,780+0,293 X 1+0,476 X 2$ dan kontribusi pengaruh sebesar 53,8\%, uji hipotesis diperoleh $F$ hitung > F tabel atau (56,404 > $2,700)$.
\end{abstract}

Keywords : Bauran Pemasaran, Kualitas Pelayanan, Kepuasan Konsumen. 


\section{PENDAHULUAN}

Pada saat ini meningkatnya penduduk di indonesia mengakibatkan menigkatnya kebutuhan masyarakat. Kebutuhan masyarakat yang sangat beragam tersebut diimbangi dengan munculnya berbagai perusahaan yang memproduksi barang dan jasa, sehingga sekarang ini banyak perusahaan-perusahaan yang bergerak dalam jenis usaha yang sama.

Dengan berkembangnnya industri tekstil yang semakin pesat saat ini, membuat konsumen semakin mudah untuk mendapatkan produk yang sesuai dengan kebutuhan dan seleranya. Seiring dengan itu, persaingan di dunia industri tekstil khususnya pakaian pun semakin ketat diantara para produsen yang bersaing dalam memprebutkan konsumen. Oleh Karena itu para produsen terlebih dahulu harus memahami konsumen, mengetahuin apa yang dibutuhkan, apa seleranya, dan melihat bagaimana konsumen mangambil keputusan dalam melakukan pembelian suatu produk.

Untuk sarana pemenuhan kebutuhan sekarang ini, pakaian merupakan pemenuhan yang sangat diperlukan untuk kebutuhan sehariharinya. Pada Tahun 1978, Giant Dept Store hanyalah sebuah store pakaian kecil yang terdapat di jalan sabang, Jakarta Pusat. Saat itu, dunia retail belum semarak sepert sekarang. Namun, Giant Dept Store yang berani tampil beda dengan konsep melayani masyarakat kelas menengah ke bawah, mampu menjadi pusat perbeoanjaan idola bagi masyarakat.

Sejak awal, Giant Dept Store konsisten di jalur bisnis garmen dan pakaian jadi. Lalu pada tahun 1985, mereka mulai mendirikan 13 store yang menyediakan beragan kebutuhan dari mulai mainan, stationary, kebutuhan harian dan makanan.

Konsumen menggunakan harga sebagai bahan pertimbangan dalam menentukan pembelian produk-produk atau tidak, kapan sebaiknya pembelian dilakukan serta berapa besar kebutuhan akan produk yang dibeli sesuai dengan kemampuan daya beli konsumen. Suatu produk harus tepat dalam penentuan dan penetapan harga jualnya sehingga dapat diterima oleh konsumen dengan tidak mengabaikan kualitas produk tersebut. Dalam keadaan normal, permintaan dan harga mempunyai hubungan yang negatif atau terbalik dimana semakin tinggi harga ditetapkan semakin kecil permintaan (Jasmani, 2018).

Giant Dept Store memang telah akrab dengan diskon, bahkan diskon tersebut juga memiliki istilah masing-masing seperti Discount time, yang mem berikan potongan harga sebesar 20 persen bagi beberapa produk merk tertentu.
Ada juga diskon ala Time Service yang memberikan pelayanan potongan harga sebesar 70 persen secara dengan jangka waktu tertentu.

Agar suatu perusahaan dapat mencapai tujuan jangka panjang, maka menajemen peruhasaan sebaiknya menetapkan terlebih dahulu sarana yang ingin dicapai melalui berbagai strategi pemasran, diantaranya strategi bauran pemasaran dan kualitas pelayanan yang mempengaruhi terhadap keputusan pembeli. Dengan adanya tahapan-tahapan yang dilewati pembeli untuk mencapai kepuasan konsumen, maka produsen perlu pemahaman yang mendalam mangenai konsumen terhadap apa saja yang menjadi pertimbangan konsumen dalam melakukan pembelian satu jenis produk pakaian, karena banyak produsen yang sesungguhnya tidak mengetahui secara tepat mengapa konsumen membeli atau tidak membeli produk yang dihasilkan oleh produsen tersebut. Produsen perlu menyatukan diri mereka secara mendalam kedalam pikiran konsumennya agar dapat lebih mengenal persepsi, nilainya, tingkah laku, kepercayaan dan cara belajar dan tentu saja kebutuhan dan keinginan. Untuk itu penelitian ini diberi judul "Pengaruh Pengaruh Bauran Pemasaran dan Kualitas Pelayanan Terhadap Kepuasan konsumen Pada Giant Dept Store Cabang BSD Tangerang".

\section{TINJAUAN PUSTAKA}

\section{Bauran Pemasaran}

Pemasaran merupakan salah satu faktor yang sangat penting dalam penetuan keberhasilan perusahaan dalam upaya pencapaian tujuannya. Oleh karena itu pengelola pemasaran yang tepat mendapatkan perhatian yang serius dari perusahaanperusahaan yang telah menyadari akan arti dan pentingnya dari pengelola pemasaran yang baik.

Kegiatan pemasaran yang meliputi perkembangan produk, penentuan harga, pendistribsian, dan promosi perlu dikombinasikan dengan tepat dan optimal agar tercapai penjualan yang maksimal, yang dikenal dengan bauran pemasaran. Bauran pemasaran ini dilakukan oleh manajer pemasaran berdasarkan pasar sasaran dan penentuan posisi produk dipasar sasaran. Kombinasi yang serasi diantara variable-variable bauran pemasaran yang dilaksanakan dengan baik apabila setiap variable memperoleh tingkatan dan posisi yang tepat dan seimbang sesuai dengan posisi yang tepat dan seimbang sesuai dengan posisi produk dan pasar sasaran.

Menurut Gugup Kismono (2015:308), pengertian marketing mix adalah kombinasi dari variabel atau kegiatan yang merupakan inti dari 
pemasaran yang terdiri dari strategi produk (product), harga (price), promosi (promotion), dan tempat (place).

\section{Kualitas Pelayanan}

Memberikan kualitas pelayanan yang baik merupakan hal yang jarang dilakukan oleh perusahaan. Perusahaan yang sangat beroreantasi pada kualitas pelayanan yang baik dapat menciptakan yang baik bagi perusahaan.

Menurut Parusuraman et.al (2017) dalam Wong Sohal (2017) mengemukakan tentang 5 dimensi kualitas pelayanan atau SERQUVAL, dimana instrumen ini dapat digunakan secara umum oleh perusahaan-perusahaan jasa didalam mengukur tingkat kualitas pelayanan yang diberikan terdiri dari: Kehandalan, Daya Tanggap, Jaminan, Empati dan Wujud Nyata (Tangible).

\section{Kepuasan Konsumen}

Menurut Ferrinadewi (2014:97) dalam model sikap terbentuk tiga komponen pembentuk sikap dalam kepuasan pelanggan yang terdiri dari komponen: kognitif, afektif, dan konatif.

a. Kognitif adalah pengetahuan dan persepsi pelanggan, yang diperoleh melalui pengalaman dengan suatu objek sikap dan informasi dari berbagai sumber. Pengetahuan dan persepsi ini biasanya berbentuk kepercayaan (belief), yaitu pelanggan mempercayai bahwa produk memiliki sejumlah atribut. Kognitif ini sering juga disebut sebagai pengetahuan dan kepercayaan pelanggan.

b. Afektif mengambarkan emosi dan perasaan pelanggan menunjukkan penilaian langsung dan umum terhadap suatu produk, apakah produk itu disukai atau tidak disukai; apakah produk itu baik atau buruk.

c. Konatif menunjukkan tindakan seseorang atau kecenderungan perilaku terhadap suatu objek, konatif berkaitan dengan tindakan atau perilaku yang akan dilakukan oleh seorang pelanggan (likelihood or tendency) dan sering juga disebut sebagai intention.

\section{METODE PENELITIAN}

Populasi dalam penelitian ini berjumlah 100 responden Giant Dept Store Cabang BSD Tangerang. Teknik pengambilan sampling dalam penelitian ini adalah samplel jenuh, dimana semua anggota populasi dijadikan sebagai sampel. Dengan demikian sampel dalam penelitian ini berjumlah 100 responden. Jenis penelitian yang dipakai adalah asosiatif, dimana tujuannya adalah untuk mengetahui pengaruh antara variabel bebas terhadap variabel terikat baik parsial maupun simultan Dalam menganalisis data digunakan uji instrumen, uji asumsi klasik, regresi, koefisien determinasi dan uji hipotesis.

\section{HASIL DAN PEMBAHASAN}

\section{Analisis Deskriptif}

Pada pengujian ini digunakan untuk mengetahui skor minimum dan maksimum, mean score dan standar deviasi dari masing-masing variabel. Adapun hasilnya sebagai berikut:

Tabel 1. Hasil Analisis Descriptive Statistics

\begin{tabular}{lc|r|r|r|r} 
& \multicolumn{7}{c}{ Descriptive Statistics } & & \multicolumn{1}{c}{$\begin{array}{c}\text { Std. } \\
\end{array}$} & $\mathrm{N}$ & Minimum & Maximum & Mean & Deviation \\
\hline $\begin{array}{l}\text { Bauran pemasaran } \\
\text { (X1) }\end{array}$ & 100 & 32 & 48 & 38.51 & 4.121 \\
\hline $\begin{array}{l}\text { Kualitas pelayanan } \\
\text { (X2) }\end{array}$ & 100 & 30 & 45 & 38.43 & 3.660 \\
\hline $\begin{array}{l}\text { Kepuasan } \\
\text { konsumen (Y) }\end{array}$ & 100 & 32 & 46 & 39.33 & 3.576 \\
\hline Valid N (listwise) & 100 & & & & \\
\hline \multicolumn{1}{c}{ Bauran } & pemasaran & diperoleh & varians
\end{tabular}
minimum sebesar 32 dan varians maximum 48 dengan mean score sebesar 3,85 dengan standar deviasi 4,121.

Kualitas pelayanan diperoleh varians minimum sebesar 30 dan varians maximum 45 dengan mean score sebesar 3,84 dengan standar deviasi 3,660.

Kepuasan konsumen diperoleh varians minimum sebesar 32 dan varians maximum 46 dengan mean score sebesar 3,93 dengan standar deviasi 3,576.

\section{Analisis Verifikatif.}

Pada analisis ini dimaksudkan untuk mengetahui pengaruh variabel independen terhadap variabel dependen. Adapun hasil pengujian sebagai berikut:

\section{a. Analisis Regresi Linier Berganda}

Uji regresi ini dimaksudkan untuk mengetahui perubahan variabel dependen jika variabel independen mengalami perubahan. Adapun hasil pengujiannya sebagai berikut.

Tabel 2. Hasil Pengujian Regresi Linier Berganda

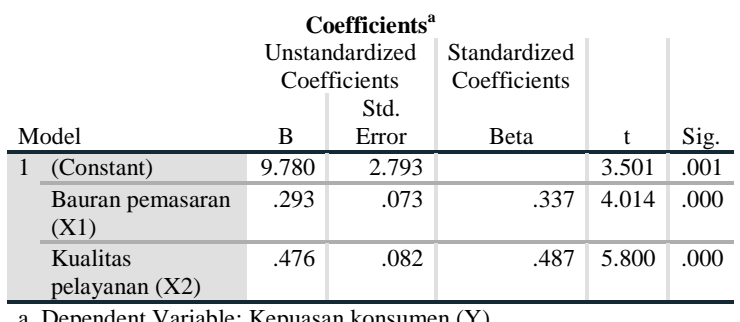

a. Dependent Variable: Kepuasan konsumen (Y) 
Berdasarkan hasil pengujian pada tabel di atas, diperoleh persamaan regresi $\mathrm{Y}=9,780+$ $0,293 X 1+0,476 X 2$. Dari persamaan tersebut dijelaskan sebagai berikut:

1) Konstanta sebesar 9,780 diartikan jika Bauran pemasaran dan kualitas pelayanan tidak ada, maka telah terdapat nilai kepuasan konsumen sebesar 9,780 point.

2) Koefisien regresi Bauran pemasaran sebesar 0,293, angka ini positif artinya setiap ada peningkatan Bauran pemasaran sebesar 0,293 maka kepuasan konsumen juga akan mengalami peningkatan sebesar 0,293 point.

3) Koefisien regresi kualitas pelayanan sebesar 0,476, angka ini positif artinya setiap ada peningkatan kualitas pelayanan sebesar 0,476 maka kepuasan konsumen juga akan mengalami peningkatan sebesar 0,476 point.

\section{b. Analisis Koefisien Korelasi}

Analisis koefisien korelasi dimaksudkan untuk mengetahui tingkt kekuatan hubungan dari variabel independen terhadap variabel dependen baik secara parsial maupun simultan. Adapun hasil pengujian sebagai berikut:

Tabel 3. Hasil Pengujian Koefisien Korelasi Bauran pemasaran Terhadap Kepuasan konsumen.

\begin{tabular}{|c|c|c|c|}
\hline \multicolumn{4}{|c|}{ Correlations $^{\mathrm{b}}$} \\
\hline & & $\begin{array}{c}\text { Bauran } \\
\text { pemasaran } \\
(\mathrm{X} 1)\end{array}$ & $\begin{array}{l}\text { Kepuasan } \\
\text { konsumen } \\
\text { (Y) }\end{array}$ \\
\hline \multirow[t]{2}{*}{$\begin{array}{l}\text { Bauran } \\
\text { pemasaran }(\mathrm{X} 1)\end{array}$} & $\begin{array}{l}\text { Pearson } \\
\text { Correlation }\end{array}$ & 1 & $.614^{* * 4}$ \\
\hline & Sig. (2-tailed) & & .000 \\
\hline \multirow[t]{2}{*}{$\begin{array}{l}\text { Kepuasan } \\
\text { konsumen (Y) }\end{array}$} & $\begin{array}{l}\text { Pearson } \\
\text { Correlation }\end{array}$ & $.614^{* *}$ & 1 \\
\hline & Sig. (2-tailed) & .000 & \\
\hline
\end{tabular}

**. Correlation is significant at the 0.01 level (2-tailed). b. Listwise $\mathrm{N}=100$

Berdasarkan hasil pengujian diperoleh nilai korelasi sebesar 0,614 artinya Bauran pemasaran memiliki hubungan yang kuat terhadap kepuasan konsumen.

Tabel 4. Hasil Pengujian Koefisien Korelasi Kualitas pelayanan Terhadap Kepuasan konsumen.

\begin{tabular}{|c|c|c|c|}
\hline \multicolumn{4}{|c|}{ Correlations $^{\mathrm{b}}$} \\
\hline & & $\begin{array}{c}\text { Kualitas } \\
\text { pelayanan } \\
\text { (X2) }\end{array}$ & $\begin{array}{l}\text { Kepuasan } \\
\text { konsumen } \\
(\mathrm{Y})\end{array}$ \\
\hline \multirow[t]{2}{*}{$\begin{array}{l}\text { Kualitas } \\
\text { pelayanan (X2) }\end{array}$} & $\begin{array}{l}\text { Pearson } \\
\text { Correlation }\end{array}$ & 1 & $.679^{* *}$ \\
\hline & Sig. (2-tailed) & & .000 \\
\hline \multirow[t]{2}{*}{$\begin{array}{l}\text { Kepuasan } \\
\text { konsumen (Y) }\end{array}$} & $\begin{array}{l}\text { Pearson } \\
\text { Correlation }\end{array}$ & $.679^{* *}$ & 1 \\
\hline & Sig. (2-tailed) & .000 & \\
\hline
\end{tabular}

b. Listwise $\mathrm{N}=100$
Berdasarkan hasil pengujian diperoleh nilai korelasi sebesar 0,679 artinya kualitas pelayanan memiliki hubungan yang kuat terhadap kepuasan konsumen.

Tabel 5. Hasil Pengujian Koefisien Korelasi Bauran pemasaran dan Kualitas pelayanan secara simultan Terhadap Kepuasan konsumen.

\begin{tabular}{ll|r|r|r} 
& \multicolumn{3}{c}{ Model Summary } \\
Model & R & R Square & $\begin{array}{l}\text { Adjusted } \\
\text { R Square }\end{array}$ & $\begin{array}{l}\text { Std. Error of } \\
\text { the Estimate }\end{array}$ \\
\hline 1 & $.733^{\mathrm{a}}$ & .538 & .528 & 2.457 \\
\hline
\end{tabular}

a. Predictors: (Constant), Kualitas pelayanan (X2), Bauran pemasaran (X1)

Berdasarkan hasil pengujian diperoleh nilai korelasi sebesar 0,733 artinya Bauran pemasaran dan kualitas pelayanan secara simultan memiliki hubungan yang kuat terhadap kepuasan konsumen.

\section{c. Analisis Koefisien Determinasi}

Analisis koefisien determinasi dimaksudkan untuk mengetahui besarnya persentase pengaruh dari variabel independen terhadap variabel dependen baik secara parsial maupun simultan. Adapun hasil pengujian sebagai berikut:

Tabel 6. Hasil Pengujian Koefisien Determinasi Bauran pemasaran Terhadap Kepuasan konsumen.

\begin{tabular}{lrr|r|r} 
& \multicolumn{3}{c}{ Model Summary } \\
Model & R & R Square & $\begin{array}{c}\text { Adjusted } \\
\text { R Square }\end{array}$ & $\begin{array}{l}\text { Std. Error of } \\
\text { the Estimate }\end{array}$ \\
\hline 1 & $.614^{\mathrm{a}}$ & .377 & .371 & 2.836 \\
\hline
\end{tabular}

a. Predictors: (Constant), Bauran pemasaran (X1)

Berdasarkan hasil pengujian diperoleh nilai determinasi sebesar 0,377 artinya Bauran pemasaran memiliki kontribusi pengaruh sebesar 37,7\% terhadap kepuasan konsumen.

Tabel 7. Hasil Pengujian Koefisien Determinasi Kualitas pelayanan Terhadap Kepuasan konsumen.

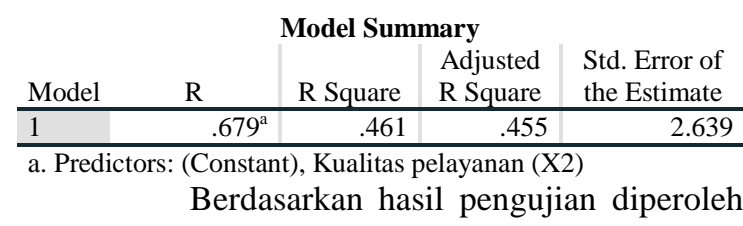
nilai determinasi sebesar 0,461 artinya kualitas pelayanan memiliki kontribusi pengaruh sebesar $46,1 \%$ terhadap kepuasan konsumen.

Tabel 8. Hasil Pengujian Koefisien Determinasi Bauran pemasaran dan Kualitas pelayanan Terhadap Kepuasan konsumen.

\begin{tabular}{ll|l|l|l} 
& \multicolumn{4}{c}{ Model Summary } \\
Model & R & R Square & Adjusted & Std. Error of \\
& R Square & the Estimate \\
\hline
\end{tabular}




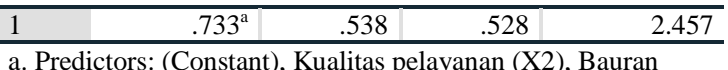
pemasaran (X1)

Berdasarkan hasil pengujian diperoleh nilai determinasi sebesar 0,538 artinya Bauran pemasaran dan kualitas pelayanan secara simultan memiliki kontribusi pengaruh sebesar 53,8\% terhadap kepuasan konsumen, sedangkan sisanya sebesar 46,2\% dipengaruhi faktor lain.

\section{d. Uji Hipotesis}

Uji hipotesis Parsial (Uji t)

Pengujian hipotesis dengan uji t digunakan untuk mengetahui hipotesis parsial mana yang diterima.

Hipotesis pertama: Terdapat pengaruh yang signifikan antara Bauran pemasaran terhadap kepuasan konsumen.

Tabel 9. Hasil Uji Hipotesis Bauran pemasaran Terhadap Kepuasan konsumen.

\begin{tabular}{|c|c|c|c|c|c|}
\hline \multirow[b]{3}{*}{ Model } & \multicolumn{3}{|c|}{ Coefficients $^{\mathrm{a}}$} & \multirow[b]{3}{*}{$\mathrm{t}$} & \multirow[b]{3}{*}{ Sig. } \\
\hline & \multicolumn{2}{|c|}{$\begin{array}{l}\text { Unstandardized } \\
\text { Coefficients }\end{array}$} & \multirow{2}{*}{$\begin{array}{c}\text { Standardized } \\
\text { Coefficients } \\
\text { Beta }\end{array}$} & & \\
\hline & B & $\begin{array}{l}\text { Std. } \\
\text { Error }\end{array}$ & & & \\
\hline 1 (Constant) & 18.800 & 2.679 & & 7.017 & .000 \\
\hline $\begin{array}{l}\text { Bauran } \\
\text { pemasaran } \\
(\mathrm{X} 1)\end{array}$ & .533 & .069 & .614 & 7.707 & .000 \\
\hline
\end{tabular}

a. Dependent Variable: Kepuasan konsumen (Y)

Berdasarkan hasil pengujian pada tabel di atas, diperoleh nilai $\mathrm{t}$ hitung $>\mathrm{t}$ tabel atau $(7,707>$ 1,984), dengan demikian hipotesis pertama yang diajukan bahwa terdapat pengaruh yang signifikan atara Bauran pemasaran terhadap kepuasan konsumen diterima.

Tabel 10. Hasil Uji Hipotesis Kualitas pelayanan Terhadap Kepuasan konsumen.

\begin{tabular}{|c|c|c|c|c|c|}
\hline \multirow[b]{3}{*}{ Model } & \multicolumn{3}{|c|}{ Coefficients $^{\mathrm{a}}$} & \multirow[b]{3}{*}{$\mathrm{t}$} & \multirow[b]{3}{*}{ Sig. } \\
\hline & \multicolumn{2}{|c|}{$\begin{array}{c}\text { Unstandardized } \\
\text { Coefficients }\end{array}$} & \multirow{2}{*}{$\begin{array}{c}\text { Standardized } \\
\text { Coefficients } \\
\text { Beta }\end{array}$} & & \\
\hline & B & $\begin{array}{l}\text { Std. } \\
\text { Error }\end{array}$ & & & \\
\hline 1 (Constant) & 13.841 & 2.797 & & 4.948 & .000 \\
\hline $\begin{array}{l}\text { Kualitas } \\
\text { pelayanan } \\
\text { (X2) }\end{array}$ & .663 & .072 & .679 & 9.153 & .000 \\
\hline
\end{tabular}

Berdasarkan hasil pengujian pada tabel di atas, diperoleh nilai $\mathrm{t}$ hitung > $\mathrm{t}$ tabel atau $(9,153>$ 1,984), dengan demikian hipotesis kedua yang diajukan bahwa terdapat pengaruh yang signifikan atara kualitas pelayanan terhadap kepuasan konsumen diterima.

\section{Uji Hipotesis Simultan (Uji F)}

Pengujian hipotesis dengan uji $\mathrm{F}$ digunakan untuk mengetahui hipotesis simultan yang mana yang diterima.

Hipotesis ketiga Terdapat pengaruh yang signifikan antara Bauran pemasaran dan kualitas pelayanan terhadap kepuasan konsumen.

Tabel 11. Hasil Uji Hipotesis Bauran pemasaran dan Kualitas pelayanan Terhadap Kepuasan konsumen.

\begin{tabular}{|c|c|c|c|c|c|c|}
\hline \multicolumn{7}{|c|}{ ANOVA $^{a}$} \\
\hline \multicolumn{2}{|c|}{ Model } & $\begin{array}{l}\text { Sum of } \\
\text { Squares }\end{array}$ & $\mathrm{df}$ & $\begin{array}{l}\text { Mean } \\
\text { Square }\end{array}$ & $\mathrm{F}$ & Sig. \\
\hline \multirow[t]{3}{*}{1} & Regression & 680.754 & 2 & 340.377 & 56.404 & $.000^{\mathrm{b}}$ \\
\hline & Residual & 585.356 & 97 & 6.035 & & \\
\hline & Total & 1266.110 & 99 & & & \\
\hline
\end{tabular}

Berdasarkan hasil pengujian pada tabel di atas, diperoleh nilai $\mathrm{F}$ hitung > F tabel atau (56,404 > 2,700), dengan demikian hipotesis ketiga yang diajukan bahwa terdapat pengaruh yang signifikan atara Bauran pemasaran dan kualitas pelayanan terhadap kepuasan konsumen diterima.

\section{PEMBAHASAN HASIL PENELITIAN}

1. Pengaruh Bauran pemasaran Terhadap Kepuasan konsumen

Bauran pemasaran berpengaruh signifikan terhadap kepuasan konsumen dengan korelasi sebesar 0,614 atau memiliki hubungan yang kuat dengan kontribusi pengaruh sebesar 37,7\%. Pengujian hipotesis diperoleh nilai $\mathrm{t}$ hitung $>\mathrm{t}$ tabel atau $(7,707>1,984)$. Dengan demikian hipotesis pertama yang diajukan bahwa terdapat berpengaruh signifikan antara Bauran pemasaran terhadap kepuasan konsumen diterima.

\section{Pengaruh Kualitas pelayanan Terhadap} Kepuasan konsumen

Kualitas pelayanan berpengaruh signifikan terhadap kepuasan konsumen dengan korelasi sebesar 0,679 atau memiliki hubungan yang kuat dengan kontribusi pengaruh sebesar 46,1\%. Pengujian hipotesis diperoleh nilai $\mathrm{t}$ hitung $>\mathrm{t}$ tabel atau $(9,153>1,984)$. Dengan demikian hipotesis kedua yang diajukan bahwa terdapat berpengaruh signifikan antara kualitas pelayanan terhadap kepuasan konsumen diterima.

\section{Pengaruh Bauran pemasaran dan Kualitas} pelayanan Terhadap Kepuasan konsumen

Bauran pemasaran dan kualitas pelayanan berpengaruh signifikan terhadap kepuasan konsumen dengan diperoleh persamaan regresi $\mathrm{Y}=$ $9,780+0,293 \mathrm{X} 1+0,476 \mathrm{X} 2$, nilai korelasi sebesar 
0,733 atau memiliki hubungan yang kuat dengan kontribusi pengaruh sebesar $53,8 \%$ sedangkan sisanya sebesar $46,2 \%$ dipengaruhi faktor lain. Pengujian hipotesis diperoleh nilai $\mathrm{F}$ hitung $>\mathrm{F}$ tabel atau (56,404 > 2,700). Dengan demikian hipotesis ketiga yang diajukan bahwa terdapat berpengaruh signifikan antara Bauran pemasaran dan kualitas pelayanan terhadap kepuasan konsumen diterima.

\section{PENUTUP}

\section{Kesimpulan}

a. Bauran pemasaran berpengaruh signifikan terhadap kepuasan konsumen dengan kontribusi pengaruh sebesar $37,7 \%$. Uji hipotesis diperoleh nilai t hitung $>\mathrm{t}$ tabel atau $(7,707>1,984)$.

b. Kualitas pelayanan berpengaruh signifikan terhadap kepuasan konsumen dengan kontribusi pengaruh sebesar $46,1 \%$. Uji hipotesis diperoleh nilai $\mathrm{t}$ hitung $>\mathrm{t}$ tabel atau $(9,153>1,984)$.

c. Bauran pemasaran dan kualitas pelayanan berpengaruh signifikan terhadap kepuasan konsumen dengan kontribusi pengaruh sebesar $53,8 \%$ sedangkan sisanya sebesar 46,2\% dipengaruhi faktor lain. Uji hipotesis diperoleh nilai $\mathrm{F}$ hitung $>\mathrm{F}$ tabel atau $(56,404>2,700)$.

\section{Saran}

a. Perusahaan harus memadukan konsep pemasaran yang terpadu dari marketing mix karena faktor-faktor tersebut mampu mendorong pelanggan untuk melakukan kepuasan konsumen.

b. Perusahaan harus memberikan penekanan pada karyawan terkait perilaku yang bersahabat melalui interaksi dari karyawan, serta fasilitas yang memadai dapat memberikan perasaan nyaman kepada konsumen memberikan kualitas pelayanan yang baik merupakan hal yang jarang dilakukan oleh perusahaan. Perusahaan yang sangat berorientasi pada kualitas pelayanan yang baik dapat menciptakan citra yang baik bagi perusahaan.

c. Untuk itu bagi perusahaan harus mengetahui bagaimana perilaku konsumen dalam melakukan kepuasan konsumen. Dalam hal ini, agar perusahaan dapat bersaing dimata konsumen, maka perusahaan sebaiknya memperhatikan beberapa fakor yang mempengaruhi kepuasan konsumen.

\section{REFERENSI}

A Sobarna, S Hambali, S Sutiswo, D Sunarsi. (2020). The influence learning used ABC run exercise on the sprint capabilities. Jurnal Konseling dan Pendidikan 8 (2), 67-71

Algifari. (2015). "Analisis Regresi untuk Bisnis dan Ekonomi”. Yogyakarta: BPFE.

Arikunto, Suharsimi (2014). "Prosedur Penelitian Suatu Pendekatan Praktek". Jakarta: Rineka Cipta.

D Sunarsi. (2014). Pengaruh Gaya Kepemimpinan, Motivasi dan Disiplin Kerja Terhadap Kinerja Pendidik. Universitas Pamulang

D Sunarsi. (2020). Kepemimpinan Bisnis Strategik. Kota Serang: Desanta Muliavisitama

Edi Sutrisno (2016). Manajemen Sumber Daya Manusia. Jakarta: Prenadamedia Group.

Fandy Tjiptono (2017), Serivce Quality and Satisfiation. Jakarta: Edisi tiga. Andi.

Freddy Rangkuti (2016) Strategi Promosi Yang Kreatif, Edisi Pertama, Cetakan Pertama Jakarta: Gramedia Pustaka Utama

Griffin R.W., \& Ronald, J.E. (2003). Dasar-Dasar Pemasaran. Jakarta: Raja

Gumilar, I., Sunarsi, D. (2020). Comparison of financial performance in banking with high car and low car (Study of banks approved in the kompas 100 index for the period 2013-2017). International Journal of Psychosocial Rehabilitation. Volume 24 - Issue 7

Hurriyati, Ratih. 2015. Bauran Pemasaran dan Loyalitas Konsumen. Alfabeta, Bandung.

Imam Ghozali (2017). "Aplikasi Analisis Multivariate Dengan Program SPSS". Edisi Kelima. Semarang: 
Badan Penerbit Undip.

Istijanto (2014) "Riset Sumber Daya Manusia". Jakarta: PT. Gramedia Pustaka

Jasmani, J. (2018). Pengaruh Kualitas Produk Dan Harga Terhadap Kepuasan konsumen Pada PT. Baja Mandiri Di Jakarta. Disrupsi Binis, 1(1).

Keller dan Amstrong (2017) "Prinsip-prinsip Pemasaran”. Edisi Kedua Belas”. Jilid Satu. Jakarta: Erlangga.

Kevin Keller dan Amstrong (2017) Prinsip-prinsip Pemasaran, Edisi Kedua Belas, Jilid Satu, Jakarta: Erlangga.

Kotler \& Keller (2016) “Manajemen Pemasaran”. PT. Macaman Jaya Cemerlang. Jakarta.

Kotler (2016) "Manajemen Pemasaran". Edisi Keempat belas, Jakarta: PT. Indeks.

Lupiyadi, Rambat (2016) Manajemen Pemasaran Jasa edisi 2 , Jakarta : Salemba Empat.

Lupiyoadi (2016) Manajemen Pemasaran Jasa, Edisi 4, Jakarta: Salemba Empat.

Maddinsyah, A., Sunarsi, D., Hermawati, R., Pranoto. (2020). Analysis of location selection effect on the user decision that influcence the success of the service business of micro, small and medium enterprise (MSME) in bandung timur region. International Journal of Advanced Science and Technology. Vol. 29 No. 06

Mani, J. (2017). Pengaruh Persepsi Merek Dan Kualitas Pelayanan Terhadap Kepuasan Pelanggan (Studi Kasus Pada PT. Bisma Narendra Di Jakarta). Jurnal Mandiri, 1(2), 187-206.

Mani, J. (2018). Pengaruh Peran Nilai Pelanggan Dan Citra Merek Terhadap Kinerja Pemasaran. Jurnal Mandiri, 2(2), 263-280.

Philip Kotler (2017) Manajemen Pemasaran, Edisi Keempat Belas, Jakarta: PT. Indeks.

Purwanti, P., Sarwani, S., \& Sunarsi, D. (2020). Pengaruh Inovasi Produk Dan Brand Awareness Terhadap Keputusan Pembelian Konsumen Pada Pt. Unilever Indonesia. Inovasi, 7(1), 24-31.

Rao, Purba, (2012). "Measuring Consumer Perceptions Through Factor Analysis", The Asian.

Santoso, Singgih (2015). "Menguasai Statistik Multivariat”. Jakarta: PT Elex Media Komputindo.

Sarwani, B Hasmanto. (2019). Investment Decision Making In Sharia Banking In Indonesia Using Analytical Hierarchy Process (Ahp) Method. Global Journal of Engineering Science and Research Management 6 (5), 40-48

Sobarna, A. (2018). Teaching Styles, Motor Skills And Sprinting Skills Learning Outcomes. IjerIndonesian Journal Of Educational Review, 5(1), 147-153.

Sudjana (2014) "Metode Statistika", Bandung: Tarsido.

Sugiyono (2017), "Metode Penelitian Administrasi : dilengkapi dengan Metode R \& D". Bandung: Alfabeta.

Suhartanto (2014). "Metode Riset Pemasaran”. Bandung: Alfabeta

Sunarsi, D. (2020). The Analysis of The Work Environmental and Organizational Cultural Impact on The Performance and Implication of The Work Satisfaction. Jurnal Ilmiah Ilmu Administrasi Publik, 9(2), 237-246. 